\title{
Reviewing reasons for the decreased CSF Abeta 42 concentration in Alzheimer disease
}

\section{Petra E. Spies ${ }^{1}$, Marcel M. Verbeek ${ }^{2,3}$, Thomas van Groen ${ }^{4,5}$, Jurgen A.H.R. Claassen ${ }^{1}$}

${ }^{I}$ Department of Geriatric Medicine, Radboud University Nijmegen Medical Center, Donders Institute for Brain, Cognition and Behaviour, and Alzheimer Center Nijmegen, Nijmegen, The Netherlands, ${ }^{2}$ Department of Neurology, Radboud University Nijmegen Medical Center, Donders Institute for Brain, Cognition and Behaviour, and Alzheimer Center Nijmegen, Nijmegen, The Netherlands, ${ }^{3}$ Department of Laboratory Medicine, Radboud University Nijmegen Medical Center, Donders Institute for Brain, Cognition and Behaviour, and Alzheimer Center Nijmegen, Nijmegen, The Netherlands, ${ }^{4}$ Department of Cell Biology, Center for Glial Biology, University of Alabama at Birmingham, Birmingham, USA, ${ }^{5}$ Department of Neurobiology, Center for Glial Biology, University of Alabama at Birmingham, Birmingham, USA

\section{TABLE OF CONTENTS}

\section{Abstract}

2. Introduction

3. Abeta $_{42}$ metabolism under normal conditions

3.1. Production of Abeta $_{42}$

3.2. Degradation of Abeta $_{42}$

3.2.1. Proteases

3.2.2. Microglia

3.3. Clearance of Abeta $_{42}$

3.3.1. Active transport of Abeta from ISF to systemic circulation

3.3.2. Drainage of Abeta with ISF to lymphatics

3.3.3. Transport of Abeta from ISF to CSF

3.3.4. Absorption of Abeta from CSF to systemic circulation

3.3.5. Drainage of Abeta with CSF to lymphatics

4. Why is CSF Abeta $_{42}$ decreased in Alzheimer disease?

4.1. Is Abeta $_{42}$ production reduced?

4.2. Is Abeta $_{42}$ degradation increased?

4.3. Is microglial uptake of Abeta $_{42}$ increased? $^{2}$

4.4. Is Abeta $_{42}$ clearance affected?

4.4.1. Is clearance of Abeta $_{42}$ from ISF increased?

4.4.2. Is transport of Abeta $_{42}$ from ISF to CSF hampered?

4.4.2.1. Hampered flow of ISF to CSF

4.4.2.2.Perivascular deposition of Abeta

4.4.2.3.Parenchymal aggregation of Abeta

5. Perspective

6. Acknowledgements

7. References

\section{ABSTRACT}

Cerebrospinal fluid (CSF) amyloid beta ${ }_{42}$ $\left(\right.$ Abeta $\left._{42}\right)$ concentrations are decreased in patients with Alzheimer disease (AD). Consequently, low Abeta $_{42}$ is considered a positive biomarker for AD. Surprisingly, the mechanisms that underlie the decrease in CSF Abeta $_{42}$ remain speculative. Better understanding of this biomarker is an essential step to unravel $\mathrm{AD}$ pathophysiology and to develop and evaluate treatment. Therefore, we systematically examined the possible reasons for the decreased CSF Abeta $_{42}$ concentration in AD. Under normal conditions, Abeta $_{42}$ can be degraded by proteases, taken up by microglia, or cleared from the brain interstitial fluid across the blood brain barrier. Alternatively, it can be transported to the CSF and be cleared from there. Aggregation of Abeta $_{42}$ appears the most likely cause for the decreased CSF Abeta $_{42}$ concentration in $\mathrm{AD}$ : the aggregated state inhibits Abeta $_{42}$ from being transported from the ISF to the CSF. Evidence for other possibilities such as a decreased production of Abeta $_{42}$, an increased proteolytic breakdown or microglial uptake of Abeta $_{42}$, or an increased clearance of Abeta $_{42}$ to the blood, is - at best scarce or even absent.

\section{INTRODUCTION}

The characteristic plaques of Alzheimer disease (AD) were discovered by Aloïs Alzheimer in 1906, but it was not until the 1980 s that it was demonstrated that these plaques consist of the amyloid beta protein (Abeta). (1-3) The realization that this protein was the same as the protein accumulating in brains of patients with Down syndrome led to the discovery of the amyloid precursor protein (APP), located on chromosome 21, as the precursor protein of Abeta. (4) Subsequently, pathogenic mutations in the APP gene were discovered in familial AD. (5-8) In the 1990s, Abeta could be measured in cerebrospinal fluid (CSF) for the first time. $(9,10)$ It was thereafter repeatedly shown that CSF Abeta $_{42}$ was decreased in AD. (11-14) Nowadays, 


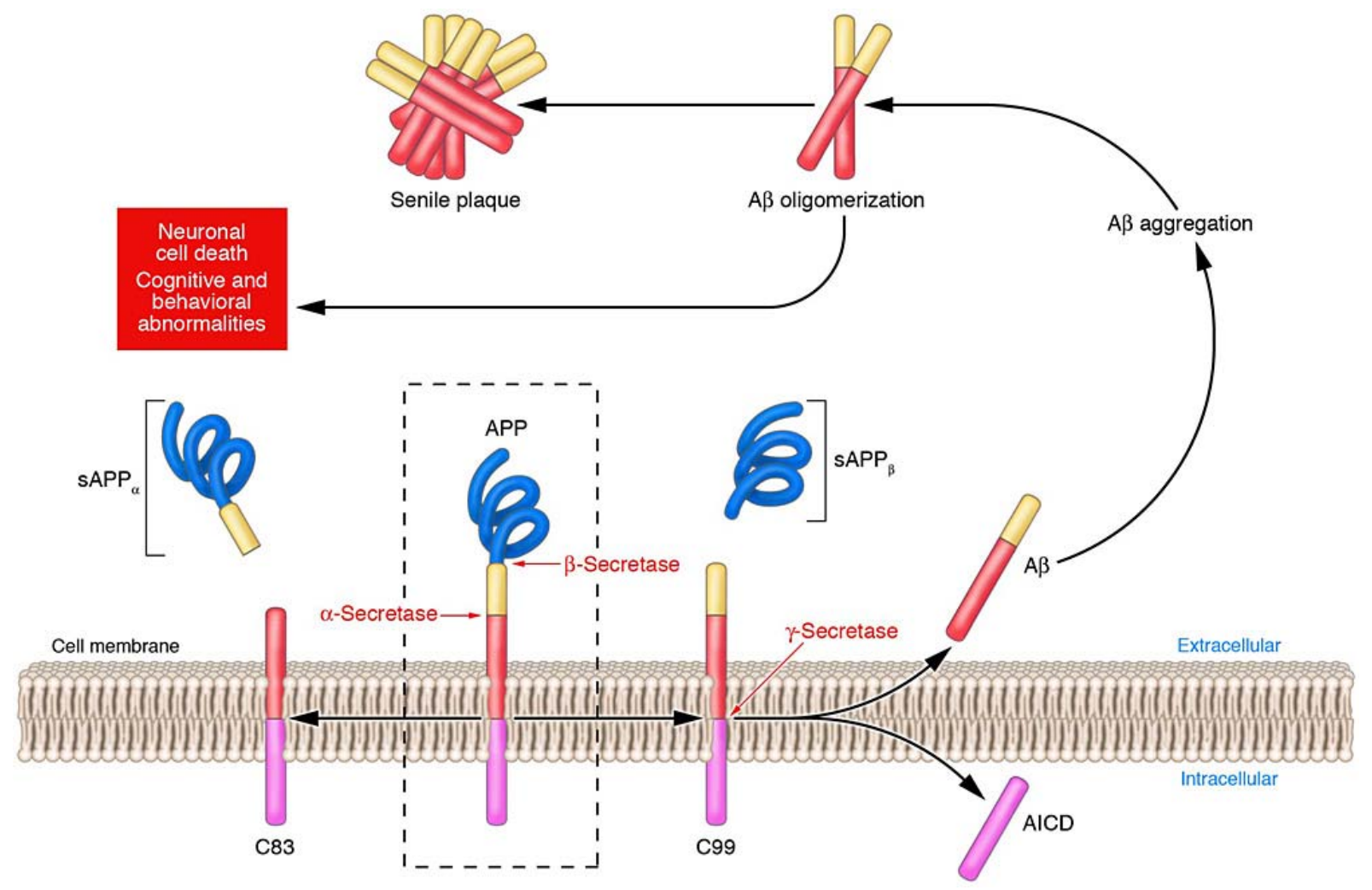

Figure 1. The non-amyloidogenic and amyloidogenic pathways of APP processing APP is cleaved by either alpha- or betasecretase. Cleavage by alpha-secretase (the non-amyloidogenic pathway) generates sAPP-alpha and C83 (left). Cleavage by betasecretase (the amyloidogenic pathway) generates sAPP-beta and C99 (right). C83 is cleaved by gamma-secretase, generating AICD and p3 (not shown). C99 is also cleaved by gamma-secretase, generating AICD and Abeta (right). (See text for abbreviations.) Republished with permission of the American Society for Clinical Investigation, from reference no. 22; permission conveyed through Copyright Clearance Center, Inc.

it is an accepted biomarker for $\operatorname{AD}(15,16)$ that is frequently used in clinical practice. $(17,18)$ Surprisingly, the cause of its decrease has not yet been fully elucidated, although several explanations have been offered: changes in Abeta generation or degradation may affect the CSF concentration, or an alteration in the solubility of Abeta42 may diminish clearance of Abeta42 from the interstitial fluid (ISF) to CSF. (11-14) Determination of the CSF Abeta42 concentration in $\mathrm{AD}$ may be masked by its interaction with binding proteins, such as apolipoprotein $\mathrm{J}$ or E, or 11. E. Matsubara, B. Frangione and J. Ghiso, Characterization of apolipoprotein J-Alzheimer's A $\beta$ interaction. J. Biol. Chem. 270 (1995), pp. 7563-7567. View Record in Scopus | Cited By in Scopuan increased clearance of Abeta42 from CSF might explain the diminished levels of Abeta42 in the CSF of AD patients. (14)

In spite of all these suggestions, the actual explanation for the decreased CSF Abeta42 in AD remains largely unidentified. Here, we will review the evidence for each of the proposed explanations to create a better understanding of the underlying mechanisms that lead to its recognition as an important $\mathrm{AD}$ biomarker.

\section{ABETA $_{42}$ METABOLISM}

\subsection{Production of Abeta $_{42}$}

Abeta $_{42}$ is produced by sequential cleavage of the amyloid precursor protein (APP) (Figure 1). APP is a membrane-bound protein whose function remains unclear, although a role in cell adhesion, cell growth and synaptogenesis has been suggested. $(19,20)$ APP can be cleaved by either alpha- or beta-secretase, and subsequently by gamma-secretase. Whether Abeta is produced from APP depends on which of these enzymes first cleaves APP.

Cleavage of APP by alpha-secretase at the plasma membrane or in the trans-Golgi network generates $\mathrm{N}$-terminal fragment soluble APP-alpha (sAPP-alpha) and C-terminal fragment C83. (21) sAPPalpha is released into intracellular vesicles or extracellularly. C83 remains membrane-bound and is cleaved by gamma-secretase to produce p3 (Abeta17-40 and Abeta17-42/43) and APP intracellular domain (AICD) (CT57-59). (22-25) The latter is released into the cytoplasm. This pathway is called the nonamyloidogenic pathway since no Abeta40 or Abeta42 is produced. 
Cleavage of APP by beta-secretase, the amyloidogenic pathway, takes place in the trans-Golgi network and in endosomes $(20,26)$ and generates $\mathrm{N}$ terminal fragment soluble APP-beta and C-terminal fragment $\mathrm{C}_{99}$. SAPP-beta - just like SAPP-alpha - can be released into intracellular vesicles or extracellularly. $\mathrm{C}_{99}$ remains membrane-bound and is subsequently cleaved by gamma-secretase to produce Abeta ${ }_{42}$ or Abeta $_{40}$ and AICD. $(22,23)$ Cleavage by gamma-secretase takes place in the endoplasmatic reticulum, trans-Golgi network, endosomes, and for a small part at the plasma membrane. (26) Other isoforms of Abeta have been identified as well, with heterogeneity either at the C- or N-terminus of the peptide, but for clarity this review will be limited to Abeta $_{42}$ and Abeta $_{40}$.

The amyloidogenic and non-amyloidogenic pathways are mutually exclusive. (22) APP molecules that are not cleaved at the cell membrane by alpha-secretase can be internalized by endocytosis and subsequently be cleaved by beta-secretase. (27) Redistribution of APP towards either the cell membrane or the cell interior can therefore influence the proteolytic pathway that APP undergoes. (22)

Abeta $_{42}$ and Abeta $_{40}$ are either retained in cells or secreted into the ISF that surrounds the brain cells. (23) The equilibrium between intra- and extracellular Abeta $_{42}$ and Abeta $_{40}$ is in part regulated by active transport via the receptor for advanced glycation end products (RAGE), (28) a multiligand receptor of the immunoglobulin family. (29)

\subsection{Degradation of Abeta $_{42}$ \\ 3.2.1. Proteases}

Several proteases can break down Abeta (both Abeta $_{42}$ and Abeta $_{40}$ ) in vitro; in vivo evidence stems mostly from animal studies. Insulin-degrading enzyme (IDE) and neprilysin have received most attention. IDE is a zincmetalloproteinase present in the cytosol, in intracellular membranes and at the cell surface. $(25,30-32)$ It is secreted by neurons (32) and has also been found in CSF. (25) It can therefore degrade both intracellular and extracellular Abeta. IDE only degrades soluble, monomeric Abeta. $(25,30,31)$ The cleavage products are not neurotoxic and are not prone to accumulate in plaques. (25) Neprilysin is an axonal and synaptic membrane-anchored protein with its catalytic site facing the cell exterior $(31,32)$ and is therefore primarily involved in the breakdown of extracellular Abeta $_{42}$. It can degrade monomeric as well as oligomeric Abeta. (32)

Other proteases that have been reported to degrade Abeta in vitro include matrix metalloproteinase- 9 , angiotensin converting enzyme, cathepsin $\mathrm{D}$, plasmin and endothelin converting enzyme-1. $(32,33)$ Abeta aggregates can stimulate tissue-type and urokinase-type plasminogen activator to generate plasmin. Plasmin can degrade both monomeric Abeta and Abeta fibrils in vitro, although degradation of fibrils is far less efficient. Its role in degrading Abeta in vivo is unclear. (33)

\subsubsection{Microglia}

Microglia are the macrophages of the brain. They take up soluble Abeta by macropinocytosis and possibly by binding of Abeta to the low-density lipoprotein receptorrelated protein (LRP). (34) Fibrillar forms of Abeta interact with the microglia cell surface and bind to the CD36 receptor expressed by microglia. CD36, a major pattern recognition receptor, mediates the microglial response to Abeta, leading to an intracellular signaling cascade that stimulates phagocytosis. (35) Ablation of microglia in mice led to an increase in soluble Abeta ${ }_{40}$ and $\mathrm{Abeta}_{42}$, but had no influence on number and size of Abeta plaques. (36) This would support the idea that microglia are inefficient in degrading fibrillar Abeta. (34) However, others have found that upon activation, for example by cerebral ischemia or after vaccination with Abeta specific antibodies, microglia can degrade fibrillar Abeta. (37-39)

\subsection{Clearance of Abeta $_{42}$}

Abeta $_{42}$ and Abeta $_{40}$ can also be cleared from the extracellular compartment. It can be cleared from the ISF across the blood-brain barrier towards the circulation, or it can be transported from the ISF to the CSF, and be cleared from there. Alternatively, Abeta can be transported with the ISF or CSF to the peripheral lymphatic system (Figure 2).

\subsubsection{Active transport of Abeta from ISF to systemic circulation}

Both Abeta $_{42}$ and Abeta $_{40}$ can be removed from ISF to the blood by crossing the blood-brain barrier. The blood-brain barrier is primarily formed by endothelial cells in brain capillaries that are closely connected via tight junctions which exclude the transfer of many macromolecules from ISF into blood. (40) Astrocytes and pericytes may also play a role in the control of transport across the blood-brain barrier. Abeta 42 and Abeta $_{40}$ are primarily transported across the blood-brain barrier by LRP. (29) LRP is a multiligand lipoprotein receptor that mediates endocytosis of secreted proteins. It provides a rapid transport of brain-derived Abeta into the blood. (41) LRP-mediated transport is more efficient for Abeta $_{40}$ when compared to $\operatorname{Abeta}_{42}(29,31)$, probably related to Abeta 40 's lower propensity to aggregate. Abeta 42 and Abeta $_{40}$ that is produced in the periphery can enter the brain ISF from the systemic circulation by active transport across the bloodbrain barrier via RAGE, which is expressed on the luminal surface of brain vessels. (29)

\subsubsection{Drainage of Abeta with ISF to lymphatics}

One of the routes that ISF can follow is drainage along axonal tracts and through perivascular spaces. ISF travels along these perivascular spaces towards the surface of the brain and exits at the base of the skull, where it drains to regional lymph nodes in the neck. (42) The idea that Abeta is transported together with ISF along this pathway is supported by the fact that Abeta has been found in the basement membranes of capillary and arterial walls, but was not detectable further downstream in the walls of the carotid arteries. (43)

\subsubsection{Transport of Abeta from ISF to CSF}

Another route for ISF is towards the CSF, where it constitutes $10-30 \%$ to the total CSF production. (44) ISF mixes with CSF at the ventricles and presumably also in the subarachnoid compartment. (40, 44) Whether Abeta 


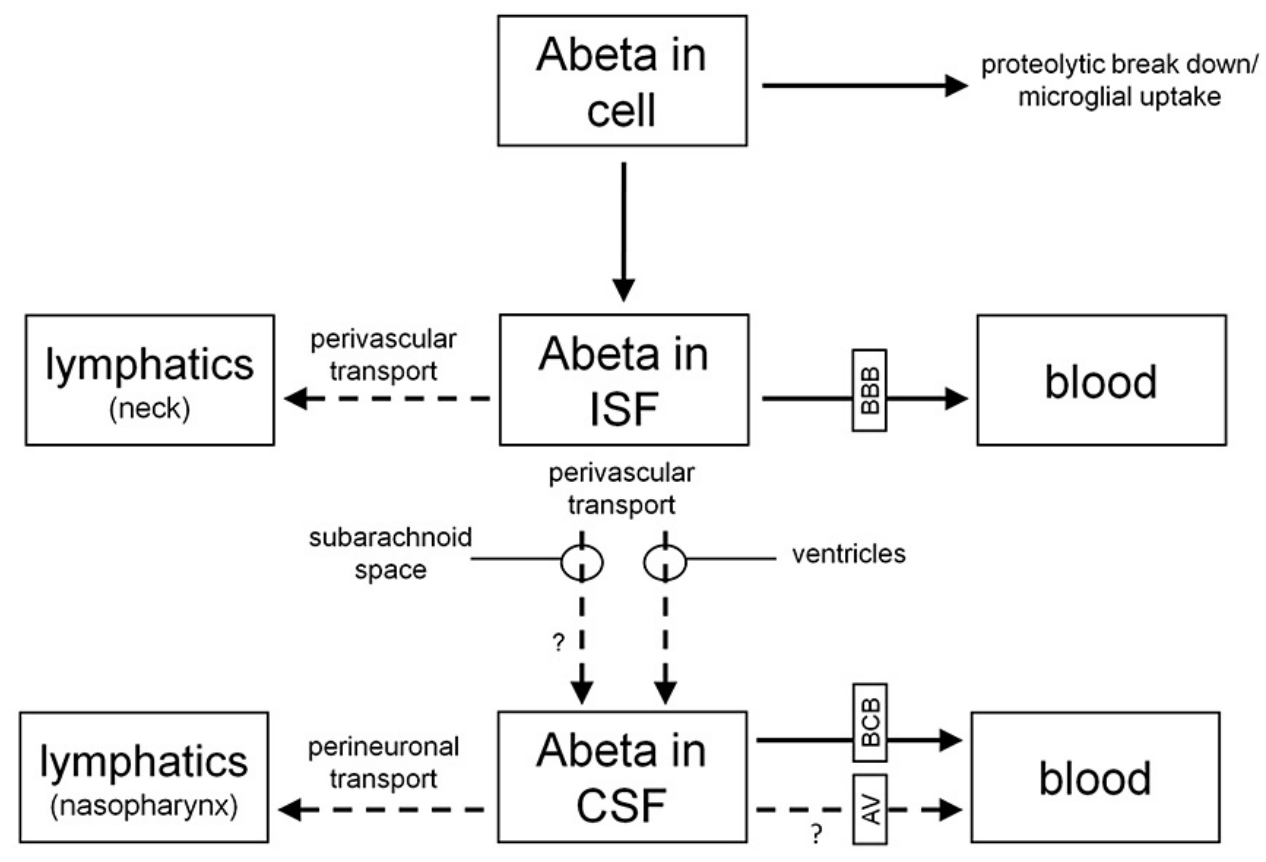

Figure 2. Schematic view of Abeta 42 and $\mathrm{Abeta}_{40}$ clearance, Abeta can be Abeta 42 or Abeta 40 . Solid arrows depict active transport of Abeta; dashed arrows depict passive transport of Abeta together with ISF or CSF.BBB = blood brain barrier, $\mathrm{BCB}=$ blood CSF barrier at choroid plexuses, $\mathrm{AV}=$ arachnoid villi

reaches the CSF via this route is uncertain. The glia limitans and the pia mater separate ISF from CSF in the subarachnoid space, however, the extent to which these layers block the passage of solutes and ISF into CSF is unknown. They may be fully permeable to fluid and small molecules, (29) but on the other hand, the presence of Abeta deposits in the glia limitans in AD suggests that transport of Abeta from ISF to CSF is limited in the subarachnoid compartment. (43)

The concentration of Abeta $_{40}$ in CSF is about 6fold greater than the concentration of $\mathrm{Abeta}_{42} ;(45-47)$ in $\mathrm{AD}$, the decreased concentration of CSF Abeta $_{42}$ makes the CSF Abeta $_{40}$ concentration at least 10-fold that of CSF Abeta $_{42} \cdot(46-48)$

\subsubsection{Absorption of Abeta from CSF to systemic circulation}

Labeled Abeta injected into CSF of rats was detectable in blood a few minutes after injection. (49) From cell culture research it was inferred that Abeta can be absorbed from CSF at the choroid plexuses. (50) The endothelium of the blood vessels within the choroid plexus is leaky, but the epithelium between blood vessels and ventricular CSF contains tight junctions and forms the blood-CSF barrier (which should not be confused with the blood-brain barrier). Small molecules can enter or leave the brain. (40) Uptake of Abeta peptides at the choroid plexus was rapid and occurred as a non-diffusional, yet unclear uptake process. Efflux of Abeta from CSF to blood was favored over influx from blood into CSF. (50) In addition to the blood-CSF barrier, CSF drains to blood in the subarachnoid compartment, where CSF drains into the major venous sinuses via arachnoid granulations. Tight junctions in these granulations prevent passage of proteins, (51) and it is therefore unclear whether Abeta can be cleared from CSF to blood in this way.

\subsubsection{Drainage of Abeta with CSF to lymphatics}

The perineural sheath along the olfactory nerve represents another pathway of CSF drainage. The olfactory nerve fibers enter the nasal mucosa in the roof of the nasal cavity. At this point CSF drains from the perineural subarachnoid space into the extracellular matrix, where it is absorbed by blind-ended lymphatic capillaries, and drained to the regional lymph nodes that serve the nasopharynx. $(44,51) \mathrm{CSF}$ also flows along the perineuronal sheaths of the cranial and spinal nerves to regional lymphatics. (40, $51,52)$ It seems plausible that Abeta is cleared together with CSF via this pathway, but studies to confirm this are currently lacking.

\section{WHY IS CSF ABETA 42 DECREASED IN ALZHEIMER DISEASE?}

Several morphological changes that are related to the fate of the $\mathrm{Abeta}_{42}$ peptide have been observed in AD. Upon post-mortem examination, Abeta plaques are found: diffuse plaques that contain only $\mathrm{Abeta}_{42}$, and classic plaques that consist of both Abeta $_{42}$ and $\operatorname{Abeta}_{40}$. $(53,54)$ In most $\mathrm{AD}$ cases, at least a mild degree of cerebral amyloid angiopathy is found as well, that consists of Abeta deposits in the walls of leptomeningeal and cortical arteries and less frequently in capillaries. (55) In contrast to the plaques, these vascular deposits contain mostly Abeta $_{40}$. (56) The concentration of both Abeta $_{42}$ and Abeta $_{40}$ in the AD brain 


\section{Decreased CSF Abeta42 in Alzheimer disease}

Table 1. Overview of arguments supporting or contradicting the hypothetical mechanisms that could explain the decreased CSF Abeta $_{42}$ concentration in AD

\begin{tabular}{|c|c|c|}
\hline Hypothetical mechanism & Supporting arguments & Contradicting arguments \\
\hline Decreased production of Abeta $_{42}$ (4.1.) & $\begin{array}{l}\text { - Could be the result of a reduction in viable neurons } \\
\text { due to neurodegeneration }\end{array}$ & $\begin{array}{l}\text { - An increased brain } \text { Abeta }_{42} \text { load is found post- } \\
\text { mortem } \\
\text { - Abeta } \\
\text { Abeta }_{42} \text { but CSF Abeta } \text { Ane }_{40} \text { is not decreased } \\
\text { - Disorders with an increased production of Abeta } \\
\text { have decreased concentrations of CSF Abeta } \\
\text { - The production of Abeta } \\
\text { from in AD did not differ } \\
\text { fromtrols in a labeling study }\end{array}$ \\
\hline Decreased secretion of Abeta $_{42}$ from neurons (4.1.) & $\begin{array}{l}\text { Intraneuronal Abeta aggregation has been } \\
\text { described in Tg mice }\end{array}$ & $\begin{array}{l}\text { - The typical Abeta plaques of AD are found } \\
\text { extracellularly }\end{array}$ \\
\hline Increased degradation of Abeta $_{42}$ (4.2.) & & $\begin{array}{l}\text { - An increased brain Abeta } 42 \text { load is found post- } \\
\text { mortem } \\
\text { - Increased degradation would probably affect } \\
\text { Abeta }_{40} \text { as well, yet the CSF Abeta } 40 \text { concentration } \\
\text { is unchanged } \\
\text { - Levels of neprilysin (one of the proteases } \\
\text { involved in Abeta degradation) decrease with } \\
\text { aging }\end{array}$ \\
\hline Increased microglial uptake of Abeta $_{42}$ (4.3.) & $\begin{array}{l}\text { - Activated microglia are found in the vicinity of } \\
\text { Abeta plaques }\end{array}$ & $\begin{array}{l}\text { - An increased brain } \text { Abeta }_{42} \text { load is found post- } \\
\text { mortem } \\
\text { - Microglia become dysfunctional with aging }\end{array}$ \\
\hline $\begin{array}{l}\text { Increased clearance of } \text { Abeta }_{42} \text { from ISF to blood } \\
(4.4 .1 .)\end{array}$ & $\begin{array}{l}\text { - Expression of LRP (which promotes transport of } \\
\text { Abeta from ISF to blood across the blood brain } \\
\text { barrier) by perivascular cells increased in reaction to } \\
\text { Abeta }_{42}\end{array}$ & $\begin{array}{l}\text { - Perivascular cells expressing LRP degenerated } \\
\text { after uptake of Abeta } \\
\text { - LRP expression is reduced in AD } \\
\text { - No increase in plasma Abeta } 42 \text { is found } \\
\text { - An increased brain } \text { Abeta }_{42} \text { load is found post- } \\
\text { mortem }\end{array}$ \\
\hline $\begin{array}{l}\text { Hampered transport of } \mathrm{Abeta}_{42} \text { with ISF to CSF } \\
(4.4 .2 .1 .)\end{array}$ & $\begin{array}{l}\text { - Dilated perivascular spaces may indicate } \\
\text { obstruction of ISF flow }\end{array}$ & $\begin{array}{l}\text { - Dilated perivascular spaces are often seen in the } \\
\text { elderly and their clinical relevance is unclear } \\
\text { - Other proteins (including Abeta }{ }_{40} \text { ) still reach the } \\
\text { CSF }\end{array}$ \\
\hline Perivascular deposition of Abeta $_{42}$ (4.4.2.2.) & - Abeta deposits are found perivascularly & $\begin{array}{l}\text { - Perivascular Abeta deposits contain mostly } \\
\text { Abeta }_{40}\end{array}$ \\
\hline $\begin{array}{l}\text { Parenchymal aggregation and deposition of } \\
\operatorname{Abeta}_{42}(4.4 .2 .3 \text {.) }\end{array}$ & $\begin{array}{l}\text { - An increased brain } \text { Abeta }_{42} \text { load is found post- } \\
\text { mortem } \\
\text { - } \text { Abeta }_{42} \text { is more prone to aggregation than Abeta } \\
40\end{array}$ & \\
\hline $\begin{array}{l}\text { Increased clearance of } \text { Abeta }_{42} \text { from CSF to the } \\
\text { blood (4.4.3.) }\end{array}$ & & $\begin{array}{l}\text { - Uptake of Abeta from CSF decreased with aging } \\
\text { - No increase in plasma Abeta } 42 \text { is found }\end{array}$ \\
\hline
\end{tabular}

The numbers behind each mechanism refer to the corresponding section in the text.

is thus increased. $(57,58)$ However, the CSF concentration of $\mathrm{Abeta}_{42}$ is decreased in $\mathrm{AD}$ patients, while the CSF Abeta $_{40}$ concentration is unaltered. $(14,48) \mathrm{We}$ will focus on reasons why CSF Abeta $_{42}$ is decreased, while keeping in mind the other changes that occur in AD. Table 1 provides an overview of these reasons and the arguments supporting or contradicting them.

\subsection{Is Abeta $_{42}$ production reduced?}

Theoretically, a decreased concentration of Abeta $_{42}$ in CSF could simply be the result of a decreased production of Abeta $_{42}$, for example by a reduction in the number of viable neurons that produce Abeta. However, several arguments make this unlikely. First, a decreased production does not logically connect to an increased Abeta $_{42}$ load in the brain. Second, if the production of Abeta $_{42}$ were decreased, the production of Abeta 40 would probably be decreased as well, since Abeta $_{42}$ and Abeta 40 likely share the same production pathway. This should then lead to a decreased CSF Abeta $_{40}$ concentration, which, however, is not observed in AD. Third, a decreased concentration of CSF Abeta $_{42}$ is also found in familial AD and in Down syndrome, disorders in which overproduction of Abeta $_{42}$ has been clearly demonstrated. (59-62) Decreased Abeta $_{42}$ thus exists despite overproduction, which implies that factors other than production play a role in causing the decreased CSF concentration.
An alternative theory is that Abeta $_{42}$ secretion from the cell is decreased, leaving less Abeta $_{42}$ available in the ISF for transport to the CSF. Although intraneuronal Abeta aggregation has been described in triple transgenic mouse models, (63) Abeta predominantly accumulates extracellularly in human AD. This implies that the secretion of Abeta from the cell to the exterior is not diminished and that a decreased secretion of Abeta $_{42}$ by the cell is unlikely to be the cause of the decreased CSF Abeta $_{42}$ concentration.

Supporting these arguments against a decreased production or secretion of $\mathrm{Abeta}_{42}$ is a study showing that the production rate of $\mathrm{Abeta}_{42}$ and $\mathrm{Abeta}_{40}$, as measured in CSF using labeled Abeta $_{42}$ and Abeta 40 , did not differ between controls and AD patients. (64)

\subsection{Is Abeta $_{42}$ degradation increased?}

It can be hypothesized that an increase in proteolytic breakdown of Abeta $_{42}$ leads to a decreased CSF Abeta $_{42}$ concentration. However, an increase in proteolytic breakdown would clear the brain from not only Abeta A $_{2}$, but also from Abeta $_{40}$ (65) and would preclude formation of plaques. Understandably, research has focused on finding defects in proteolytic degradation of Abeta rather than overactivity of these proteases to explain the elevated cerebral levels of Abeta. $(32,33)$ It appears that levels of 
neprilysin decrease with aging (66) and that low levels of neprilysin make certain brain areas more vulnerable to Abeta deposition, $(67,68)$ suggesting that proteolytic activity is decreased rather than increased.

\subsection{Is microglial uptake of Abeta $_{42}$ increased?}

An increased microglial uptake of Abeta $_{42}$ could be hypothesized to lead to the decreased CSF Abeta concentration by leaving less Abeta $_{42}$ available in the ISF for transport to the CSF. Activated microglia are found in the vicinity of compact Abeta plaques, (69) however, the very presence of these plaques shows that microglial uptake of Abeta is insufficient to lead to a lower-than-normal concentration of Abeta in ISF. On the contrary, it has been suggested that with age, microglia become dysfunctional and less able to clear Abeta $_{42}$. $(34,70,71)$ Thus, it is unlikely that microglial ability to degrade Abeta is increased in $\mathrm{AD}$.

\subsection{Is Abeta $_{42}$ clearance affected?}

Changes in the clearance of Abeta from either ISF or CSF (the solid arrows in Figure 1) can influence the Abeta concentration. An increased transport of ISF or CSF, containing Abeta, to the lymphatics will not affect the Abeta concentration.

\subsubsection{Is clearance of Abeta $_{42}$ from ISF increased?}

An increased clearance of Abeta $_{42}$ from ISF to blood across the blood-brain barrier would leave a smaller amount of $\mathrm{Abeta}_{42}$ in the ISF that can be transported to the CSF and could thus explain the decreased CSF Abeta 42 concentration. The primary transporter of Abeta across the blood-brain barrier is LRP. Even though LRP favors clearance of Abeta $_{40}$ over Abeta $_{42}$, it can be hypothesized that in $\mathrm{AD}$, clearance of $\mathrm{Abeta}_{42}$ is upregulated while clearance of Abeta $_{40}$ remains the same. In support of this hypothesis, expression of LRP by perivascular cells was increased in response to Abeta $_{42}$ in vitro, while Abeta $_{40}$ had no such effect; however, uptake of Abeta resulted in degeneration of these perivascular cells. (72) It has also been reported that LRP expression was reduced in AD, while RAGE expression (which transports Abeta from blood to brain) was increased. (29) These changes do not support an increased clearance of Abeta $_{42}$ from ISF over the bloodbrain barrier and could actually lead to a reduced transport of Abeta $_{42}$ out of the brain and an increased uptake of peripheral Abeta $_{42}$ into the brain.

Another argument against an increased transport of Abeta $_{42}$ across the blood-brain barrier is the lack of an increase in plasma Abeta $_{42}$ concentration. Increased transport of Abeta $_{42}$ to the blood should result in an increase in the plasma concentration of Abeta $_{42}-$ assuming that the peripheral breakdown and elimination of $\mathrm{Abeta}_{42}$ are not increased in AD. Reports on the plasma Abeta $_{42}$ concentration in $\mathrm{AD}$ patients are contradictory, but a clear increase has not been shown. $(73,74)$ Finally, enhanced clearance of $A_{b e t a}$ from the ISF is incompatible with the increased Abeta load that is found in AD brains. In summary, it cannot be concluded that transport across the blood-brain barrier is increased.
4.4.2. Is transport of Abeta $_{42}$ from ISF to CSF hampered?

\subsubsection{Hampered flow of ISF to CSF}

ISF flows through the perivascular spaces, mixing with CSF in the subarachnoid compartment at the brain surface and at the ventricles. If $\mathrm{Abeta}_{42}$-containing ISF cannot reach the CSF or if Abeta $_{42}$ is deposited before ISF reaches the CSF, the Abeta $_{42}$ concentration in CSF will be decreased. Dilated perivascular spaces may be interpreted as a sign that ISF cannot, or has difficulty to, reach the CSF. (75) However, dilated perivascular spaces are often seen in the elderly and are not AD-specific. (76) Their clinical relevance is unclear. The fact that Abeta $_{40}$ and other proteins can still reach the CSF in AD argues against an obstruction of transport between ISF and CSF.

\subsubsection{Perivascular deposition of Abeta}

Signs that Abeta $_{42}$ is deposited before it reaches the CSF are present: Abeta deposits are found in the walls of the cerebral vasculature and in the glia limitans in the subarachnoid compartment. $(43,77,78)$ The deposits in the cerebral vasculature consist mostly of Abeta $_{40}$, and to a lesser extent of $A_{b e t a}$. (56) In clinically diagnosed cerebral amyloid angiopathy, a decreased CSF Abeta 40 concentration was found. (79) This suggests that perivascular Abeta deposition can indeed lead to a decreased CSF Abeta concentration. However, cerebral amyloid angiopathy found in $\mathrm{AD}$ is mostly mild to moderate, (55) and the amount of Abeta $_{42}$ that is deposited in the cerebral vasculature is presumably insufficient to be the sole explanation for the decreased CSF Abeta 42 concentration.

\subsubsection{Parenchymal aggregation of Abeta}

Aggregation of $\mathrm{Abeta}_{42}$ into insoluble deposits may be a reason why Abeta $_{42}$ is decreased in CSF: less soluble Abeta $_{42}$ is left for transport to the CSF, while the insoluble aggregates cannot be transported from ISF to the CSF. Abeta 42 is much more prone to aggregation than Abeta $_{40}$. $(56,80)$ Both diffuse and classic plaques contain Abeta $_{42}$, but only the classic plaques, which are fewer in number, contain Abeta $_{40}$. (54) Thus, much more Abeta 42 than Abeta $_{40}$ is deposited in AD. Considering that Abeta 40 is the most abundant Abeta peptide in CSF, (81) the relative amount that is deposited in $\mathrm{AD}$ may be too little to induce a clear decrease in the CSF Abeta 40 concentration. In contrast, the relative amount of Abeta $_{42}$ that is deposited is much larger, which may explain why the CSF Abeta 42 concentration is decreased.

\subsubsection{Is CSF Abeta An $_{42}$ decreased because more Abeta An $_{42}$ is cleared from CSF?}

Uptake of Abeta $_{42}$ from the CSF was inferred from research in cell culture that used Abeta $_{40}$ as a model compound for all Abeta species. (50) Theoretically, this process could be upregulated in $\mathrm{AD}$, resulting in more Abeta $_{42}$ to be transported from the CSF into the blood. Since the CSF Abeta $_{40}$ concentration is unaltered, this upregulation should then selectively affect $\mathrm{Abeta}_{42}$ and not Abeta $_{40}$. Research to confirm this is currently lacking. In contrast, research in rats suggests that uptake of Abeta from the CSF decreases with aging. (82) Furthermore, the 
increase in the plasma concentration of Abeta $_{42}$ that would be expected if upregulated efflux was the case (and peripheral elimination of Abeta was unaltered), has not been shown convincingly. $(73,74)$ Therefore it seems unlikely that an increased clearance of Abeta $_{42}$ from the CSF is the cause of the decreased CSF Abeta 42 concentration in AD.

\section{PERSPECTIVE}

We have reviewed a number of possible mechanisms that could theoretically explain the typical observation of a decreased CSF Abeta $_{42}$ concentration in AD. It appears very difficult to understand the decrease in CSF Abeta $_{42}$ found in AD. Based on simple but systematic reasoning, a number of theoretical mechanisms can be formulated, however, most of these do not concur with the premise that there is an increased Abeta load in the AD brain, and that the decreased CSF Abeta $_{42}$ is accompanied by an unaltered CSF Abeta $_{40}$ concentration. Furthermore, many of these theoretical mechanisms are contradicted by (often fragmented) findings from research. For example, a decreased production of Abeta $_{42}$ has not been shown: production rates were comparable between controls and $\mathrm{AD}$ patients. Increased proteolytic breakdown of Abeta is unlikely, since available evidence suggests a decrease in proteolytic activity rather than an increase. An increased microglial uptake of Abeta $_{42}$ is not supported, instead, a decrease in activity with aging is found. Increased clearance of $\mathrm{Abeta}_{42}$ from either ISF or CSF has not been reported; rather, decreases in clearance have been suggested.

What, in our opinion, remains as the most plausible cause of the decreased Abeta $_{42}$ concentration in CSF is Abeta $_{42}$ aggregation. Abeta 42 is known to aggregate easily and once aggregates have been formed, transport of these aggregates from the ISF to the CSF may be seriously impaired. Abeta ${ }_{40}$ has different properties and is not as prone to aggregation, which may explain why less Abeta $_{40}$ is found deposited in the $\mathrm{AD}$ brain, and why CSF concentrations of Abeta $_{40}$ are unaltered.

Until novel mechanistic insights with respect to the different steps in Abeta metabolism are obtained, this remains currently the most satisfying explanation for the observed Abeta changes in AD. Our systematic approach may have provided a framework against which the currently available knowledge from research can be laid out, as pieces of a puzzle. In this way, CSF Abeta $_{42}$ can be much more than a diagnostic test with an empirical cut-off value for use in clinical settings. Better understanding of this biomarker may be the key to a better understanding of the disease.

\section{ACKNOWLEDGEMENTS}

Marcel Verbeek is supported by grants from the Internationale Stichting Alzheimer Onderzoek (ISAO, no. 07510), the Netherlands Organisation for Scientific Research (NWO/ZonMW, Vidi program, no. 917.46.331) and the Hersenstichting Nederland (no. 14F06.18).
Jurgen Claassen receives grants from Alzheimer Nederland and has received consulting fees from Novartis and lecture fees from Janssen.

\section{REFERENCES}

1. P. D. Gorevic, F. Goni, B. Pons-Estel, F. Alvarez, N. S. Peress and B. Frangione: Isolation and partial characterization of neurofibrillary tangles and amyloid plaque core in Alzheimer's disease: immunohistological studies. J Neuropathol Exp Neurol 45, 647-664 (1986)

2. C. L. Masters, G. Simms, N. A. Weinman, G. Multhaup, B. L. McDonald and K. Beyreuther: Amyloid plaque core protein in Alzheimer disease and Down syndrome. Proc Natl Acad Sci U S A 82, 4245-4249 (1985)

3. A. Roher, D. Wolfe, M. Palutke and D. KuKuruga: Purification, ultrastructure, and chemical analysis of Alzheimer disease amyloid plaque core protein. Proc Natl Acad Sci U S A 83, 2662-2666 (1986)

4. J. Kang, H. G. Lemaire, A. Unterbeck, J. M. Salbaum, C. L. Masters, K. H. Grzeschik, G. Multhaup, K. Beyreuther and B. Muller-Hill: The precursor of Alzheimer's disease amyloid A4 protein resembles a cell-surface receptor. Nature 325, 733-736 (1987)

5. M. C. Chartier-Harlin, F. Crawford, H. Houlden, A. Warren, D. Hughes, L. Fidani, A. Goate, M. Rossor, P. Roques and J. Hardy: Early-onset alzheimer's disease caused by mutations at codon 717 of the beta-amyloid precursor protein gene. Nature 353, 844-846 (1991)

6. A. Goate, M. C. Chartier-Harlin, M. Mullan, J. Brown, F. Crawford, L. Fidani, L. Giuffra, A. Haynes, N. Irving and L. James: Segregation of a missense mutation in the amyloid precursor protein gene with familial Alzheimer's disease. Nature 349, 704-706 (1991)

7. M. Mullan, F. Crawford, K. Axelman, H. Houlden, L. Lilius, B. Winblad and L. Lannfelt: A pathogenic mutation for probable Alzheimer's disease in the APP gene at the Nterminus of beta-amyloid. Nat Genet 1, 345-347 (1992)

8. J. Murrell, M. Farlow, B. Ghetti and M. D. Benson: A mutation in the amyloid precursor protein associated with hereditary Alzheimer's disease. Science 254, $97-99$ (1991)

9. P. Seubert, C. Vigo-Pelfrey, F. Esch, M. Lee, H. Dovey, D. Davis, S. Sinha, M. Schlossmacher, J. Whaley and C. Swindlehurst: Isolation and quantification of soluble Alzheimer's beta-peptide from biological fluids. Nature 359, 325-327 (1992)

10. M. Shoji, T. E. Golde, J. Ghiso, T. T. Cheung, S. Estus, L. M. Shaffer, X. D. Cai, D. M. McKay, R. Tintner and B. Frangione: Production of the Alzheimer amyloid beta protein by normal proteolytic processing. Science 258, 126-129 (1992)

11. D. Galasko, L. Chang, R. Motter, C. M. Clark, J. Kaye, D. Knopman, R. Thomas, D. Kholodenko, D. Schenk, I. 
Lieberburg, B. Miller, R. Green, R. Basherad, L. Kertiles, M. A. Boss and P. Seubert: High cerebrospinal fluid tau and low amyloid beta42 levels in the clinical diagnosis of Alzheimer disease and relation to apolipoprotein E genotype. Arch Neurol 55, 937-945 (1998)

12. R. Motter, C. Vigo-Pelfrey, D. Kholodenko, R. Barbour, K. Johnson-Wood, D. Galasko, L. Chang, B. Miller, C. Clark and R. Green: Reduction of beta-amyloid peptide42 in the cerebrospinal fluid of patients with Alzheimer's disease. Ann Neurol 38, 643-648 (1995)

13. M. Shoji, E. Matsubara, M. Kanai, M. Watanabe, T. Nakamura, Y. Tomidokoro, M. Shizuka, K. Wakabayashi, Y. Igeta, Y. Ikeda, K. Mizushima, M. Amari, K. Ishiguro, T. Kawarabayashi, Y. Harigaya, K. Okamoto and S. Hirai: Combination assay of CSF tau, A beta 1-40 and A beta 142 (43) as a biochemical marker of Alzheimer's disease. $J$ Neurol Sci 158, 134-140 (1998)

14. A. Tamaoka, N. Sawamura, T. Fukushima, S. Shoji, E. Matsubara, M. Shoji, S. Hirai, Y. Furiya, R. Endoh and H. Mori: Amyloid beta protein 42 (43) in cerebrospinal fluid of patients with Alzheimer's disease. J Neurol Sci 148, 4145 (1997)

15. B. Dubois, H. H. Feldman, C. Jacova, S. T. DeKosky, P. Barberger-Gateau, J. Cummings, A. Delacourte, D. Galasko, S. Gauthier, G. Jicha, K. Meguro, J. O'Brien, F. Pasquier, P. Robert, M. Rossor, S. Salloway, Y. Stern, P. J. Visser and P. Scheltens: Research criteria for the diagnosis of Alzheimer's disease: revising the NINCDS-ADRDA criteria. Lancet Neurol 6, 734-746 (2007)

16. G. M. McKhann, D. S. Knopman, H. Chertkow, B. T. Hyman, C. R. Jack, Jr., C. H. Kawas, W. E. Klunk, W. J. Koroshetz, J. J. Manly, R. Mayeux, R. C. Mohs, J. C. Morris, M. N. Rossor, P. Scheltens, M. C. Carrillo, B. Thies, S. Weintraub and C. H. Phelps: The diagnosis of dementia due to Alzheimer's disease: Recommendations from the National Institute on Aging-Alzheimer's Association workgroups on diagnostic guidelines for Alzheimer's disease. Alzheimers Dement 7, 263-269 (2011)

17. D. Slats, P. E. Spies, M. J. Sjogren, P. J. Visser, M. M. Verbeek, M. G. Olde Rikkert and P. G. Kehoe: CSF biomarker utilisation and ethical considerations of biomarker assisted diagnosis and research in dementia: perspectives from within the European Alzheimer's Disease Consortium (EADC). J Neurol Neurosurg Psychiatry 81, 124-125 (2010)

18. P. E. Spies, D. Slats, I. Ramakers, F. Verhey and M. G. Olde Rikkert: Experiences with cerebrospinal fluid analysis in Dutch memory clinics. Eur $J$ Neurol DOI: 10.1111/j.1468-1331.2010.03222.x, (2011)

19. M. P. Marzolo, G. Bu: Lipoprotein receptors and cholesterol in APP trafficking and proteolytic processing, implications for Alzheimer's disease. Semin Cell Dev Biol 20, 191-200 (2009)
20. G. Thinakaran, E. H. Koo: Amyloid precursor protein trafficking, processing, and function. J Biol Chem 283, 29615-29619 (2008)

21. D. M. Skovronsky, D. B. Moore, M. E. Milla, R. W. Doms and V. M. Lee: Protein kinase C-dependent alphasecretase competes with beta-secretase for cleavage of amyloid-beta precursor protein in the trans-golgi network. $J$ Biol Chem 275, 2568-2575 (2000)

22. S. Gandy: The role of cerebral amyloid beta accumulation in common forms of Alzheimer disease. $J$ Clin Invest 115, 1121-1129 (2005)

23. S. Kumar-Singh: Cerebral amyloid angiopathy: pathogenetic mechanisms and link to dense amyloid plaques. Genes Brain Behav 7 Suppl 1, 67-82 (2008)

24. Q. X. Li, S. J. Fuller, K. Beyreuther and C. L. Masters: The amyloid precursor protein of Alzheimer disease in human brain and blood. J Leukoc Biol 66, 567-574 (1999)

25. Y. H. Suh, F. Checler: Amyloid precursor protein, presenilins, and alpha-synuclein: molecular pathogenesis and pharmacological applications in Alzheimer's disease. Pharmacol Rev 54, 469-525 (2002)

26. K. S. Vetrivel, G. Thinakaran: Amyloidogenic processing of beta-amyloid precursor protein in intracellular compartments. Neurology 66, S69-S73 (2006)

27. F. Kamenetz, T. Tomita, H. Hsieh, G. Seabrook, D. Borchelt, T. Iwatsubo, S. Sisodia and R. Malinow: APP processing and synaptic function. Neuron 37, 925-937 (2003)

28. A. Rauk: The chemistry of Alzheimer's disease. Chem Soc Rev 38, 2698-2715 (2009)

29. R. Deane, R. D. Bell, A. Sagare and B. V. Zlokovic: Clearance of amyloid-beta peptide across the blood-brain barrier: implication for therapies in Alzheimer's disease. CNS Neurol Disord Drug Targets 8, 16-30 (2009)

30. W. Farris, S. Mansourian, Y. Chang, L. Lindsley, E. A. Eckman, M. P. Frosch, C. B. Eckman, R. E. Tanzi, D. J. Selkoe and S. Guenette: Insulin-degrading enzyme regulates the levels of insulin, amyloid beta-protein, and the beta-amyloid precursor protein intracellular domain in vivo. Proc Natl Acad Sci U S A 100, 4162-4167 (2003)

31. R. E. Tanzi, R. D. Moir and S. L. Wagner: Clearance of Alzheimer's Abeta peptide: the many roads to perdition. Neuron 43, 605-608 (2004)

32. A. J. Turner, L. Fisk and N. N. Nalivaeva: Targeting amyloid-degrading enzymes as therapeutic strategies in neurodegeneration. Ann N Y Acad Sci 1035, 1-20 (2004)

33. D. J. Selkoe: Clearing the brain's amyloid cobwebs. Neuron 32, 177-180 (2001) 
34. C. Y. Lee, G. E. Landreth: The role of microglia in amyloid clearance from the AD brain. J Neural Transm $117,949-960$ (2010)

35. J. B. El Khoury, K. J. Moore, T. K. Means, J. Leung, K. Terada, M. Toft, M. W. Freeman and A. D. Luster: CD36 mediates the innate host response to beta-amyloid. $J$ Exp Med 197, 1657-1666 (2003)

36. S. A. Grathwohl, R. E. Kalin, T. Bolmont, S. Prokop, G. Winkelmann, S. A. Kaeser, J. Odenthal, R. Radde, T. Eldh, S. Gandy, A. Aguzzi, M. Staufenbiel, P. M. Mathews, H. Wolburg, F. L. Heppner and M. Jucker: Formation and maintenance of Alzheimer's disease betaamyloid plaques in the absence of microglia. Nat Neurosci 12, 1361-1363 (2009)

37. H. Akiyama, P. L. McGeer: Specificity of mechanisms for plaque removal after A beta immunotherapy for Alzheimer disease. Nat Med 10, 117-118 (2004)

38. A. Majumdar, D. Cruz, N. Asamoah, A. Buxbaum, I. Sohar, P. Lobel and F. R. Maxfield: Activation of microglia acidifies lysosomes and leads to degradation of Alzheimer amyloid fibrils. Mol Biol Cell 18, 1490-1496 (2007)

39. J. A. Nicoll, E. Barton, D. Boche, J. W. Neal, I. Ferrer, P. Thompson, C. Vlachouli, D. Wilkinson, A. Bayer, D. Games, P. Seubert, D. Schenk and C. Holmes: Abeta species removal after abeta42 immunization. J Neuropathol Exp Neurol 65, 1040-1048 (2006)

40. N. J. Abbott: Evidence for bulk flow of brain interstitial fluid: significance for physiology and pathology. Neurochem Int 45, 545-552 (2004)

41. R. Deane, Z. Wu, A. Sagare, J. Davis, Y. S. Du, K. Hamm, F. Xu, M. Parisi, B. LaRue, H. W. Hu, P. Spijkers, H. Guo, X. Song, P. J. Lenting, W. E. Van Nostrand and B. V. Zlokovic: LRP/amyloid beta-peptide interaction mediates differential brain efflux of Abeta isoforms. Neuron 43, 333-344 (2004)

42. R. O. Weller, M. Subash, S. D. Preston, I. Mazanti and R. O. Carare: Perivascular drainage of amyloid-beta peptides from the brain and its failure in cerebral amyloid angiopathy and Alzheimer's disease. Brain Pathol 18, 253-266 (2008)

43. R. O. Weller, E. Djuanda, H. Y. Yow and R. O. Carare: Lymphatic drainage of the brain and the pathophysiology of neurological disease. Acta Neuropathol 117, 1-14 (2009)

44. M. Johnston: The importance of lymphatics in cerebrospinal fluid transport. Lymphat Res Biol 1, 41-44 (2003)

45. O. Hansson, H. Zetterberg, P. Buchhave, U. Andreasson, E. Londos, L. Minthon and K. Blennow: Prediction of Alzheimer's disease using the CSF Abeta42/Abeta40 ratio in patients with mild cognitive impairment. Dement Geriatr Cogn Disord 23, 316-320 (2007)

46. P. Lewczuk, H. Esselmann, M. Otto, J. M. Maler, A. W. Henkel, M. K. Henkel, O. Eikenberg, C. Antz, W. R. Krause, U. Reulbach, J. Kornhuber and J. Wiltfang: Neurochemical diagnosis of Alzheimer's dementia by CSF Abeta42, Abeta42/Abeta40 ratio and total tau. Neurobiol Aging 25, 273-281 (2004)

47. M. Kanai, E. Matsubara, K. Isoe, K. Urakami, K. Nakashima, H. Arai, H. Sasaki, K. Abe, T. Iwatsubo, T. Kosaka, M. Watanabe, Y. Tomidokoro, M. Shizuka, K. Mizushima, T. Nakamura, Y. Igeta, Y. Ikeda, M. Amari, T. Kawarabayashi, K. Ishiguro, Y. Harigaya, K. Wakabayashi, K. Okamoto, S. Hirai and M. Shoji: Longitudinal study of cerebrospinal fluid levels of tau, A beta1-40, and A beta142 (43) in Alzheimer's disease: a study in Japan. Ann Neurol 44, 17-26 (1998)

48. P. E. Spies, D. Slats, J. M. Sjogren, B. P. Kremer, F. R. Verhey, M. G. Olde Rikkert and M. M. Verbeek: The cerebrospinal fluid amyloid beta42/40 ratio in the differentiation of Alzheimer's disease from nonAlzheimer's dementia. Curr Alzheimer Res 7, 470-476 (2010)

49. J. F. Ghersi-Egea, P. D. Gorevic, J. Ghiso, B. Frangione, C. S. Patlak and J. D. Fenstermacher: Fate of cerebrospinal fluid-borne amyloid beta-peptide: rapid clearance into blood and appreciable accumulation by cerebral arteries. J Neurochem 67, 880-883 (1996)

50. J. S. Crossgrove, G. J. Li and W. Zheng: The choroid plexus removes beta-amyloid from brain cerebrospinal fluid. Exp Biol Med (Maywood) 230, 771-776 (2005)

51. K. G. Kapoor, S. E. Katz, D. M. Grzybowski and M. Lubow: Cerebrospinal fluid outflow: an evolving perspective. Brain Res Bull 77, 327-334 (2008)

52. M. Johnston, C. Papaiconomou: Cerebrospinal fluid transport: a lymphatic perspective. News Physiol Sci 17, 227-230 (2002)

53. T. Iwatsubo, A. Odaka, N. Suzuki, H. Mizusawa, N. Nukina and Y. Ihara: Visualization of A beta 42 (43) and A beta 40 in senile plaques with end-specific A beta monoclonals: evidence that an initially deposited species is A beta 42 (43). Neuron 13, 45-53 (1994)

54. M. M. Verbeek, P. Eikelenboom and R. M. De Waal: Differences between the pathogenesis of senile plaques and congophilic angiopathy in Alzheimer disease. $J$ Neuropathol Exp Neurol 56, 751-761 (1997)

55. A. A. Rensink, R. M. De Waal, B. Kremer and M. M. Verbeek: Pathogenesis of cerebral amyloid angiopathy. Brain Res Brain Res Rev 43, 207-223 (2003)

56. S. A. Gravina, L. Ho, C. B. Eckman, K. E. Long, L. Otvos, Jr., L. H. Younkin, N. Suzuki and S. G. Younkin: 
Amyloid beta protein (A beta) in Alzheimer's disease brain. Biochemical and immunocytochemical analysis with antibodies specific for forms ending at A beta 40 or A beta 42 (43). J Biol Chem 270, 7013-7016 (1995)

57. H. Funato, M. Yoshimura, K. Kusui, A. Tamaoka, K. Ishikawa, N. Ohkoshi, K. Namekata, R. Okeda and Y. Ihara: Quantitation of amyloid beta-protein (A beta) in the cortex during aging and in Alzheimer's disease. $\mathrm{Am} \mathrm{J}$ Pathol 152, 1633-1640 (1998)

58. Y. Harigaya, M. Shoji, T. Kawarabayashi, M. Kanai, T. Nakamura, T. Iizuka, Y. Igeta, T. C. Saido, N. Sahara and H. Mori: Modified amyloid beta protein ending at 42 or 40 with different solubility accumulates in the brain of Alzheimer's disease. Biochem Biophys Res Commun 211, 1015-1022 (1995)

59. M. Moonis, J. M. Swearer, M. P. Dayaw, P. St GeorgeHyslop, E. Rogaeva, T. Kawarai and D. A. Pollen: Familial Alzheimer disease: decreases in CSF Abeta42 levels precede cognitive decline. Neurology 65, 323-325 (2005)

60. E. Portelius, U. Andreasson, J. M. Ringman, K. Buerger, J. Daborg, P. Buchhave, O. Hansson, A. Harmsen, M. K. Gustavsson, E. Hanse, D. Galasko, H. Hampel, K. Blennow and H. Zetterberg: Distinct cerebrospinal fluid amyloid beta peptide signatures in sporadic and PSEN1 A431E-associated familial Alzheimer's disease. Mol Neurodegener 5, 2 (2010)

61. A. Tamaoka, Y. Sekijima, S. Matsuno, T. Tokuda, S. Shoji and S. I. Ikeda: Amyloid beta protein species in cerebrospinal fluid and in brain from patients with Down's syndrome. Ann Neurol 46, 933 (1999)

62. T. Tapiola, H. Soininen and T. Pirttila: CSF tau and Abeta42 levels in patients with Down's syndrome. Neurology 56, 979-980 (2001)

63. F. M. LaFerla, K. N. Green and S. Oddo: Intracellular amyloid-beta in Alzheimer's disease. Nat Rev Neurosci 8, 499-509 (2007)

64. K. G. Mawuenyega, W. Sigurdson, V. Ovod, L. Munsell, T. Kasten, J. C. Morris, K. E. Yarasheski and R. J. Bateman: Decreased clearance of CNS beta-amyloid in Alzheimer's disease. Science 330, 1774 (2010)

65. M. A. Leissring, W. Farris, A. Y. Chang, D. M. Walsh, X. Wu, X. Sun, M. P. Frosch and D. J. Selkoe: Enhanced proteolysis of beta-amyloid in APP transgenic mice prevents plaque formation, secondary pathology, and premature death. Neuron 40, 1087-1093 (2003)

66. J. Apelt, K. Ach and R. Schliebs: Aging-related downregulation of neprilysin, a putative beta-amyloid-degrading enzyme, in transgenic Tg2576 Alzheimer-like mouse brain is accompanied by an astroglial upregulation in the vicinity of beta-amyloid plaques. Neurosci Lett 339, 183-186 (2003)
67. H. Akiyama, H. Kondo, K. Ikeda, M. Kato and P. L. McGeer: Immunohistochemical localization of neprilysin in the human cerebral cortex: inverse association with vulnerability to amyloid beta-protein (Abeta) deposition. Brain Res 902, 277-281 (2001)

68. K. Yasojima, H. Akiyama, E. G. McGeer and P. L. McGeer: Reduced neprilysin in high plaque areas of Alzheimer brain: a possible relationship to deficient degradation of beta-amyloid peptide. Neurosci Lett 297, 97-100 (2001)

69. T. Ohgami, T. Kitamoto, R. W. Shin, Y. Kaneko, K. Ogomori and J. Tateishi: Increased senile plaques without microglia in Alzheimer's disease. Acta Neuropathol 81, 242-247 (1991)

70. W. J. Streit, J. R. Conde, S. E. Fendrick, B. E. Flanary and C. L. Mariani: Role of microglia in the central nervous system's immune response. Neurol Res 27, 685-691 (2005)

71. W. J. Streit: Microglial senescence: does the brain's immune system have an expiration date? Trends Neurosci 29, 506-510 (2006)

72. M. M. Wilhelmus, I. Otte-Holler, J. J. van Triel, R. Veerhuis, M. L. Maat-Schieman, G. Bu, R. M. De Waal and M. M. Verbeek: Lipoprotein receptor-related protein-1 mediates amyloid-beta-mediated cell death of cerebrovascular cells. Am J Pathol 171, 1989-1999 (2007)

73. V. Giedraitis, J. Sundelof, M. C. Irizarry, N. Garevik, B. T. Hyman, L. O. Wahlund, M. Ingelsson and L. Lannfelt: The normal equilibrium between CSF and plasma amyloid beta levels is disrupted in Alzheimer's disease. Neurosci Lett 427, 127-131 (2007)

74. T. Kawarabayashi, M. Shoji: Plasma biomarkers of Alzheimer's disease. Curr Opin Psychiatry 21, 260-267 (2008)

75. A. E. Roher, Y. M. Kuo, C. Esh, C. Knebel, N. Weiss, W. Kalback, D. C. Luehrs, J. L. Childress, T. G. Beach, R. O. Weller and T. A. Kokjohn: Cortical and leptomeningeal cerebrovascular amyloid and white matter pathology in Alzheimer's disease. Mol Med 9, 112-122 (2003)

76. Y. C. Zhu, C. Dufouil, B. Mazoyer, A. Soumare, F. Ricolfi, C. Tzourio and H. Chabriat: Frequency and Location of Dilated Virchow-Robin Spaces in Elderly People: A Population-Based 3D MR Imaging Study. AJNR Am J Neuroradiol 32, 709-713 (2011)

77. R. O. Weller: How well does the CSF inform upon pathology in the brain in Creutzfeldt-Jakob and Alzheimer's diseases? J Pathol 194, 1-3 (2001)

78. J. Attems, F. Lintner and K. A. Jellinger: Amyloid beta peptide 1-42 highly correlates with capillary cerebral amyloid angiopathy and Alzheimer disease pathology. Acta Neuropathol 107, 283-291 (2004) 


\section{Decreased CSF Abeta42 in Alzheimer disease}

79. M. M. Verbeek, B. P. Kremer, M. O. Rikkert, P. H. Van Domburg, M. E. Skehan and S. M. Greenberg: Cerebrospinal fluid amyloid beta (40) is decreased in cerebral amyloid angiopathy. Ann Neurol 66, 245-249 (2009)

80. J. T. Jarrett, E. P. Berger and P. T. Lansbury, Jr.: The carboxy terminus of the beta amyloid protein is critical for the seeding of amyloid formation: implications for the pathogenesis of Alzheimer's disease. Biochemistry 32, 4693-4697 (1993)

81. J. Wiltfang, H. Esselmann, M. Bibl, A. Smirnov, M. Otto, S. Paul, B. Schmidt, H. W. Klafki, M. Maler, T. Dyrks, M. Bienert, M. Beyermann, E. Ruther and J. Kornhuber: Highly conserved and disease-specific patterns of carboxyterminally truncated Abeta peptides 1-37/38/39 in addition to 1-40/42 in Alzheimer's disease and in patients with chronic neuroinflammation. J Neurochem 81, 481-496 (2002)

82. J. E. Preston: Ageing choroid plexus-cerebrospinal fluid system. Microsc Res Tech 52, 31-37 (2001)

Key words: Dementia, Cerebrospinal fluid, Amyloid-beta peptides, Biomarker, Review

Send correspondence to: Petra E. Spies, Department of Geriatric Medicine, 925, Radboud University Nijmegen Medical Center, P.O. Box 9101, 6500 HB Nijmegen, The Netherlands, Tel.: 3124361 6772, Fax: 3124361 7408, Email: PetraESpies@gmail.com 